\title{
Campylobacter jejuni and Campylobacter coli in wild birds on Danish livestock farms
}

\author{
Birthe Hald ${ }^{1,6^{*}}$, Marianne Nielsine Skov 2,7, Eva Møller Nielsen²,8, Carsten Rahbek, ${ }^{3,5,9}$, Jesper Johannes Madsen ${ }^{3}$, \\ Michael Wain $\varnothing^{1,10}$, Mariann Chriél ${ }^{4,11}$, Steen Nordentoft ${ }^{1,12}$, Dorte Lau Baggesen ${ }^{2,6}$ and Mogens Madsen ${ }^{1,13}$
}

\begin{abstract}
Background: Reducing the occurrence of campylobacteriosis is a food safety issue of high priority, as in recent years it has been the most commonly reported zoonosis in the EU. Livestock farms are of particular interest, since cattle, swine and poultry are common reservoirs of Campylobacter spp. The farm environment provides attractive foraging and breeding habitats for some bird species reported to carry thermophilic Campylobacter spp. We investigated the Campylobacter spp. carriage rates in 52 wild bird species present on 12 Danish farms, sampled during a winter and a summer season, in order to study the factors influencing the prevalence in wild birds according to their ecological guild. In total, 1607 individual wild bird cloacal swab samples and 386 livestock manure samples were cultured for Campylobacter spp. according to the Nordic Committee on Food Analysis method NMKL 119.

Results: The highest Campylobacter spp. prevalence was seen in 110 out of 178 thrushes (61.8\%), of which the majority were Common Blackbird (Turdus merula), and in 131 out of 616 sparrows (21.3\%), a guild made up of House Sparrow (Passer domesticus) and Eurasian Tree Sparrow (Passer montanus). In general, birds feeding on a diet of animal or mixed animal and vegetable origin, foraging on the ground and vegetation in close proximity to livestock stables were more likely to carry Campylobacter spp. in both summer $(P<0.001)$ and winter $(P<0.001)$ than birds foraging further away from the farm or in the air. Age, fat score, gender, and migration range were not found to be associated with Campylobacter spp. carriage. A correlation was found between the prevalence (\%) of C. jejuni in wild birds and the proportions (\%) of $C$. jejuni in both manure on cattle farms $\left(R^{2}=0.92\right)$ and poultry farms $\left(R^{2}=0.54\right)$, and between the prevalence (\%) of C. coli in wild birds and the proportions (\%) of C. coli in manure on pig farms $\left(R^{2}=0.62\right)$.

Conclusions: The ecological guild of wild birds influences the prevalence of Campylobacter spp. through the behavioural patterns of the birds. More specifically, wild birds eating food of animal or mixed animal and vegetable origin and foraging on the ground close to livestock were more likely to carry Campylobacter spp. than those foraging further away or hunting in the air. These findings suggest that wild birds may play a role in sustaining the epidemiology of Campylobacter spp. on farms.
\end{abstract}

Keywords: Campylobacter spp. epidemiology, C. jejuni, C. coli, Wild birds, Livestock farms, Ecological guild, Cattle, Pig, Poultry

\section{Background}

Human campylobacteriosis has been the most commonly reported zoonosis in the European Union (EU) since 2005, with 214,779 confirmed cases in 2013 according to the European Food Safety Authority (EFSA) [1]. The disease

\footnotetext{
*Correspondence: bhal@food.dtu.dk

${ }^{6}$ Present Address: National Food Institute, Technical University

of Denmark, 2860 Søborg, Denmark

Full list of author information is available at the end of the article
}

burden was calculated at 35,000 disability-adjusted life years (DALYs) per year and the annual cost in the EU at around $€ 2.4$ billion [2]. The global number of DALYs was calculated to be 7,541,000 per year [3]. The cause of campylobacteriosis is Campylobacter spp. (primarily $C$. jejuni and C. coli)-a Gram-negative, spiral, microaerophilic bacterium and a common commensal inhabitant of the intestinal microflora of food production animals such as cattle, pigs and poultry [4]. It is estimated that 50-80\% 
of Campylobacter spp. strains infecting humans originate from the chicken reservoir, $20-30 \%$ from the cattle reservoir and a small proportion from other reservoirs including wild animals [5]. As a consequence, the entire meat production chain and end products may be contaminated with $C$. jejuni or C. coli. In the EU, the pathways to humans are mainly through food, though environmental transmission and direct animal contact are also possible [6]. Therefore, reducing the occurrence of campylobacteriosis in the EU is a food safety issue of high priority, yet one which presents challenges [7].

According to a recent and extensive systematic review of 95 published studies of Campylobacter spp. sources around broiler farms [8], several wild animals (including wild birds) are known to be carriers. However, only a small number of the reviewed studies had a primary focus on wild birds living in close proximity to the farms. On a broiler farm in Athens GA, USA, 10 \% (of 124) wild birds-mainly House Sparrow (Passer domesticus) and Common Starling (Sturnus vulgaris)-carried C. jejuni [9]. Colles et al. [10] found C. jejuni in $50.2 \%$ of droppings from 331 Canada Goose (Branta canadensis) and Greylag Goose (Anser anser), and in 29.9 \% of 954 Common Starling on a free-range broiler farm. Concerning cattle farms, a study in central Iowa, USA sampled 188 wild birds on dairy cattle, sheep and goat farms and found Campylobacter spp. in $4.8 \%$ [11].

During the past decade, source attribution studies including multilocus sequence typing (MLST) have been conducted to compare the similarity of $C$. jejuni strains from wild birds with those from chicken and cattle [10$15]$ and with isolates from human disease [10, 12, 13, 1517]. The overall conclusion is that the vast majority of $C$. jejuni strains are highly host specific. However, the studies also all identified a small proportion of strains with genotypes overlapping wild birds, farm animals [10-15] and human disease isolates [10,13,15-17].

Several studies on Campylobacter spp. carriage rates in wild birds in urban areas report a prevalence from 0-90\% [18-24]. Although it would appear that wild birds living in cities (mainly sparrows, pigeons, doves and starlings) have low carriage rates [19, 20, 22], French et al. [16] suggested that wild birds in city parks could contribute to campylobacteriosis in preschool children. The overall highest reported carriage rates have been found in gulls and crows foraging on refuse dumps in urban areas of Norway, Sweden, England, Japan, Spain and USA [1821, 23-25].

Some of the large discrepancies in wild bird Campylobacter spp. prevalence between different studies may be attributed to host taxonomy or differences in the ecological guilds present. Bird ecological guilds are groupings of birds that exploit environmental resources in a similar way $[26,27]$. The significance of different ecological guilds on the carriage rates of Campylobacter spp. was shown in a study of 1794 birds (the majority of which were migratory), sampled at Ottenby Bird Observatory on the island Oeland, Sweden [28]. The highest prevalence of Campylobacter spp. was found among ground-foraging guilds of short-distance migratory birds wintering in Europe.

The aim of our study was to estimate the prevalence of Campylobacter spp. in farm related wild bird species. Additionally, to investigate an association between Campylobacter spp. contaminated farm environments and wild birds around cattle, pig and poultry farms by performing an analysis of factors associated with Campylobacter spp. carriage of the wild birds.

\section{Methods}

\section{Study design and selection of farms}

The study covered four cattle farms, four slaughter pig farms, and four free-range poultry farms in Denmark, together with the wild bird populations living inside production buildings or within a $100 \mathrm{~m}$ radius from the farms. The study was conducted during January and February (winter) and during August and September (summer) in 2001. Two farms were sampled per week, and visited every weekday in order to get as many wild bird samples as possible. The cattle and pig farms were initially selected for a project investigating the occurrence of Salmonella in wildlife near Danish cattle and pig farms during 2001 and 2002 [29], while the poultry farms were included in this study only. The sampling schemes for Campylobacter spp. and Salmonella were conducted simultaneously in 2001.

\section{Sampling \\ Wild birds}

Birds were caught and ringed following the EURING system (http://www.euring.org/) by licensed ringers with mist-nets, traps, or by hand, thus ensuring that each bird was only sampled once per sampling event. The birds were released again after sampling. To ensure that a sufficient number of birds were caught during the winter months, several feeding places were established at each herd, using sterilised birdseed. We sampled as many birds as possible, and data on the estimated age, fat score, gender and exact place of capture were noted. Cloacal swab samples were obtained from the wild birds, using slim aluminum cotton swabs (DANSU, Ganløse, Denmark) and placed in Brain Heart Infusion (BHI) transport medium (DIFCO, Sparks, MD, USA) containing $5 \%$ (v/v) calf blood (National Veterinary Institute, Copenhagen, Denmark) and $0.5 \%$ agar (Oxoid Ltd., Basingstoke, Hampshire, UK). 


\section{Production animals}

To detect Campylobacter spp. in cattle and pig herds, manure was collected at numerous places in the livestock facilities or among herds in pasture, and mixed into approximately twenty $200 \mathrm{ml}$ containers (Dispatch Container Nunc, Life Technologies, Nærum, Denmark) per herd in each sampling round (i.e. 5-10 manure samples per container equalling $150-180 \mathrm{ml}$ of manure) in order to obtain a representative measure of the within-herd Campylobacter spp. status. In order to sample poultry flocks, material from the litter surface was collected on a pair of boot socks whilst walking through the flock's resting house [30].

\section{Bacteriological examination and species characterisation}

All samples were transported to the laboratory on the sampling day at ambient temperature, refrigerated overnight between 2 and $4{ }^{\circ} \mathrm{C}$, and Campylobacter spp. cultivation was initiated the following day. For the number of samples tested, see Table 1.

\section{Cloacal swabs}

Campylobacter spp. were isolated by streaking a swab with the faecal material directly on to modified Charcoal Cefoperazone Deoxycholate Agar (mCCDA) (CM0739, SR0155) (Oxoid) [31], and the plates were incubated under microaerobic conditions $\left(6 \% \mathrm{O}_{2}, 6 \% \mathrm{CO}_{2}\right.$, in $88 \%$ $\mathrm{N}_{2}$ ) at $42{ }^{\circ} \mathrm{C}$ for 48 h. Campylobacter spp.-like colonies were purified on blood agar and identified to species level using standard procedures including tests for hippurate and indoxyl acetate hydrolysis, catalase production and susceptibility to cephalotin and nalidixic acid according to NMKL 119 [32]. Campylobacter spp. isolates were identified as C. jejuni, C. coli, C. lari, C. upsaliensis, C. hyointestinalis or Campylobacter spp.

\section{Manure}

The manure was diluted to $1 \mathrm{~g}$ per $9 \mathrm{ml}$ of buffered peptone water (CM1049, Oxoid), and $10 \mu \mathrm{l}$ of the suspended material was streaked on mCCDA and incubated as described above.

\section{Boot socks}

Each pair of boot socks was placed in a stomacher bag, and after being diluted in 1:10 w/w in buffered peptone water (CM1049, Oxoid), faeces were released by gentle manipulation and $10 \mu \mathrm{l}$ of the suspension was spread on mCCDA and incubated as described above.

\section{Data analysis}

The dependent variable was defined as a positive isolation of Campylobacter spp. from a wild bird. Descriptive

Table 1 Campylobacter spp. prevalence and species distribution

\begin{tabular}{|c|c|c|c|c|c|}
\hline Origin of sample & $\begin{array}{l}\text { Number } \\
\text { of samples }\end{array}$ & $\begin{array}{l}\text { Total number } \\
\text { (\%) positive }\end{array}$ & $\begin{array}{l}\text { Number } \\
\text { of C. jejuni (\%) }\end{array}$ & $\begin{array}{l}\text { Number } \\
\text { of C. coli (\%) }\end{array}$ & $\begin{array}{l}\text { Number of other } \\
\text { C. spp. (\%) }\end{array}$ \\
\hline \multicolumn{6}{|l|}{ Winter } \\
\hline \multicolumn{6}{|l|}{ Cattle farms } \\
\hline Wild birds & 268 & $36(13.4)$ & $22(8.2)$ & $13(4.9)$ & $1(0.4)$ \\
\hline Cattle manure & 81 & $36(44.4)$ & $32(39.5)$ & $2(2.5)$ & $2(2.5)$ \\
\hline \multicolumn{6}{|l|}{ Pig farms } \\
\hline Wild birds & 288 & $64(22.2)$ & $33(11.5)$ & $27(9.4)$ & $4(1.4)$ \\
\hline Pig manure & 81 & 72 (88.9) & $0(0.0)$ & $69(85.2)$ & $3(3.7)$ \\
\hline \multicolumn{6}{|l|}{ Poultry farms } \\
\hline Wild birds & 150 & $16(10.7)$ & $10(6.7)$ & $6(4.0)$ & $0(0.0)$ \\
\hline Poultry manure & 8 & $1(12.5)$ & $1(12.5)$ & $0(0.0)$ & $0(0.0)$ \\
\hline \multicolumn{6}{|l|}{ Summer } \\
\hline \multicolumn{6}{|l|}{ Cattle farms } \\
\hline Wild birds & 253 & $38(15.0)$ & $36(14.2)$ & $0(0.0)$ & $2(0.8)$ \\
\hline Cattle manure & 83 & $55(66.3)$ & $54(65.1)$ & $0(0.0)$ & $1(1.2)$ \\
\hline \multicolumn{6}{|l|}{ Pig farms } \\
\hline Wild birds & 330 & $69(20.9)$ & $68(20.6)$ & $1(0.3)$ & $0(0.0)$ \\
\hline Pig manure & 83 & $54(65.1)$ & $4(4.8)$ & $50(60.2)$ & $0(0.0)$ \\
\hline \multicolumn{6}{|l|}{ Poultry farms } \\
\hline Wild birds & 318 & $73(23.0)$ & $70(22.0)$ & $1(0.3)$ & $2(0.6)$ \\
\hline Poultry manure & 50 & $45(90.0)$ & $41(82.0)$ & $4(8.0)$ & $0(0.0)$ \\
\hline
\end{tabular}

The number of samples tested for Campylobacter spp., the total number and percentage of positive samples, and the numbers of $C$. jejuni, C. coli and other Campylobacter spp. positive samples isolated in wild birds and in livestock manure on each farm type in winter and summer 
statistics were performed using bivariate analysis [33] on Campylobacter spp. positive samples from wild birds. The association between independent variables was assessed using the Chi square test with a statistical significance threshold of $P<0.05$. The evaluation of a possible association between Campylobacter spp. positive samples in the wild birds and in the herd was carried out separately for the two seasons (winter and summer).

Six potential factors associated with Campylobacter spp. carriage were included: (1) age (old, young); (2) herd type (cattle, pig, poultry); (3) proximity (in stable, around stable); (4) ecological guild with $\geq 10$ samples (i.e. aerial insectivorous, foliage-gleaners, insectivorous seedeaters, open-land insectivorous, tit-like birds, sparrows, passerine seedeaters, terrestrial and low fly-catching feeders and thrushes); (5) fat score (0-8) [34], and (6) gender (male, female, not determined).

Based on the characteristic behaviour patterns of each ecological guild, the following five factors were selected: (1) feed (animal, mix, vegetable); (2) forage area (aerial, ground, vegetation); (3) proximity to stables (in stable, around stable); (4) contact with slurry (no, yes), and (5) migration range (long, medium, short, partial, none). This analysis included only the summer sampling, as more guilds were present, and the birds exhibited a wider range of behavioural patterns during the summer season than in winter.

Multivariate analyses [33] were carried out in all sampled wild birds organised in an ecological guild structure based on Gotellia et al. [27], using SAS Enterprise guide ver. 3.0.2. The logistic regression analyses were carried out using SAS PROC GENMOD. The modelling procedure assumed a binomial distribution and used logit as the link function. Goodness of fit was assessed by likelihood ratio statistics. The model was adjusted for overdispersion using the PSCALE option. In the analysis, non-significant variables were removed using stepwise backwards elimination. Statistical significance of the covariates was assessed using the likelihood ratio test based on $P \leq 0.05$. The odds ratio (OR) and the $95 \%$ confidence interval were reported for statistically significant variables.

In order to evaluate the impact of different herd types and season on the $C$. jejuni and $C$. coli carriage rates, sparrows $(n=616)$ were selected for the analysis, since this guild of non-migratory wild birds was the only one to be caught in a sufficient number on all farms during both winter and summer sampling. Correlation coefficients $\left(\mathrm{R}^{2}\right)$ were calculated between the prevalence (\%) of $C$. jejuni and C. coli in sparrows and the proportions (\%) C. jejuni and C. coli in manure from each of the three herd types.

\section{Results}

Campylobacter spp. prevalence in sampled wild birds

In total, 1607 wild birds were sampled. The overall Campylobacter spp. carriage rate was significantly lower in winter $(15.9 \%, 112$ positive samples out of a total of $706)$ than in summer $(20.0 \%, 180$ positive samples out of a total of $901 ; \mathrm{OR}=1.32,1.02-1.71, P=0.03$ ). For the species of Campylobacter spp. detected in each farm type, and the carriage rate among wild birds in winter and summer, see Table 1. For the prevalence of Campylobacter spp. in each bird species, see Table 2 and grouped in ecological guilds, see Table 3.

The Campylobacter spp. carriage rates varied considerably between ecological guilds. The highest prevalence was found within two guilds: thrushes with $61.8 \%$ $(110 / 178)$ positive samples and sparrows with $21.3 \%$ $(131 / 616)$ positive samples (Table 2). Combined, these guilds were responsible for $82.5 \%$ (241 out of 292) of the positive wild bird samples. The main bird species of these two guilds were the Common Blackbird (Turdus merula; $\mathrm{n}=174)$, House Sparrow $(\mathrm{n}=366)$ and Eurasian Tree Sparrow (Passer montanus; $\mathrm{n}=250$ ). They were also the most frequently sampled wild birds on the farms. Other birds that were frequently present were the Barn Swallow (Hirundu rustica; $\mathrm{n}=128$ ), Great Tit (Parus major; $\mathrm{n}=129$ ), European Greenfinch (Carduelis chloris; $\mathrm{n}=90$ ) and Common House Martin (Delichon urbica; $\mathrm{n}=83$ ), all of which had a low Campylobacter spp. prevalence (Table 2).

\section{Factors associated with Campylobacter spp. carriage in wild birds}

Analysis of the six selected risk factors for Campylobacter spp. carriage in wild birds (age, herd type, proximity, ecological guild, fat score and gender) revealed that the ecological guild was significantly associated with Campylobacter spp. carriage during both winter and summer (Table 3). Thrushes and open-land insectivorous birds were more likely to carry Campylobacter spp. than sparrows (used as a reference guild), whereas all other guilds had lower odds than sparrows. In general, herd type, fat score, gender and age were not significantly associated with Campylobacter spp. prevalence in wild birds (all sampled birds). Proximity was significant in summer (see proximity to stables in Table 4) but not in winter (data not shown).

\section{Patterns of behaviour in summer}

Concerning the impact of particular patterns of behaviour in summer (i.e. feed, forage area, proximity to stables, contact with slurry and migration range), there was significantly increased odds for Campylobacter spp. carriage in 
Table 2 The prevalence of Campylobacter spp. in wild birds and the allocation of bird species to ecological guild

\begin{tabular}{|c|c|c|c|c|c|}
\hline Ecological guilds & Species & Common name & $\begin{array}{l}\text { Number } \\
\text { tested W/S }\end{array}$ & $\begin{array}{l}\text { Number } \\
\text { positive W/S }\end{array}$ & $\begin{array}{l}\% \text { Campylobacter } \\
\text { positive W/S }\end{array}$ \\
\hline \multirow[t]{4}{*}{ Aerial insectivorous } & Delichon urbicum & Common house martin & $0 / 83$ & $0 / 0$ & $0.0 / 0.0$ \\
\hline & Delichon urbicum (brood) & Common house martin, brood & $0 / 2$ & $0 / 0$ & $0.0 / 0.0$ \\
\hline & Hirundu rustica & Barn swallow & $0 / 128$ & $0 / 10$ & $0.0 / 7.8$ \\
\hline & Hirundu rustica (brood) & Barn swallow, brood & $0 / 21$ & $0 / 4$ & $0.0 / 19.0$ \\
\hline Bud-browser and seedeaters & Pyrrhula pyrrhula & Eurasian bullfinch & $1 / 5$ & $0 / 0$ & $0.0 / 0.0$ \\
\hline \multirow[t]{3}{*}{ Columbids } & Columba livia domesticus & Feral pigeon & $3 / 3$ & $1 / 0$ & $33.3 / 0.0$ \\
\hline & Columba palumbus & Common wood pigeon & $0 / 1$ & $0 / 0$ & $0.0 / 0.0$ \\
\hline & Streptopelia decaocto & Eurasian collared dove & $2 / 3$ & $0 / 0$ & $0.0 / 0.0$ \\
\hline Flycatcher & Muscicapa striata & Spotted flycatcher & $0 / 2$ & $0 / 1$ & $0.0 / 50.0$ \\
\hline \multirow[t]{8}{*}{ Foliage-gleaners } & Fringilla coelebs & Common chaffinch & $26 / 2$ & $0 / 0$ & $0.0 / 0.0$ \\
\hline & Hippolais icterina & Icterine warbler & $0 / 1$ & $0 / 0$ & $0.0 / 0.0$ \\
\hline & Phylloscopus collybita & Common chiffchaff & $0 / 12$ & $0 / 0$ & $0.0 / 0.0$ \\
\hline & Phylloscopus trochilus & Willow warbler & $0 / 18$ & $0 / 3$ & $0.0 / 16.7$ \\
\hline & Sylvia atricapilla & Eurasian blackcap & $0 / 9$ & $0 / 2$ & $0.0 / 22.2$ \\
\hline & Sylvia borin & Garden warbler & $0 / 9$ & $0 / 0$ & $0.0 / 0.0$ \\
\hline & Sylvia communis & Common whitethroat & $0 / 44$ & $0 / 5$ & $0.0 / 11.4$ \\
\hline & Sylvia curruca & Lesser whitethroat & $0 / 9$ & $0 / 3$ & $0.0 / 33.3$ \\
\hline Gallinaceous birds & Phasianus colchicus & Common pheasant & $1 / 0$ & $0 / 0$ & $0.0 / 0.0$ \\
\hline Gulls & Larus canus & Mew gull & $2 / 0$ & $0 / 0$ & $0.0 / 0.0$ \\
\hline \multirow[t]{2}{*}{ Insectivorous seedeaters } & Emberiza citrinella & Yellowhammer & $2 / 19$ & $0 / 3$ & $0.0 / 15.8$ \\
\hline & Emberiza calandra & Corn bunting & $0 / 3$ & $0 / 1$ & $0.0 / 33.3$ \\
\hline \multirow[t]{2}{*}{ Marshwarblers } & Acrocephalus palustris & Marsh warbler & $0 / 5$ & $0 / 0$ & $0.0 / 0.0$ \\
\hline & Acrocephalus scirpaceus & Eurasian reed warbler & $0 / 1$ & $0 / 0$ & $0.0 / 0.0$ \\
\hline Omnivorous corvidae & Corvus frugilegus & Rook & $2 / 0$ & $0 / 0$ & $0.0 / 0.0$ \\
\hline \multirow[t]{4}{*}{ Open-land insectivorous } & Alauda arvensis & Eurasian skylark & $0 / 1$ & $0 / 0$ & $0.0 / 0.0$ \\
\hline & Anthus trivialis & Tree pipit & $0 / 1$ & $0 / 0$ & $0.0 / 0.0$ \\
\hline & Motacilla alba & White wagtail & $0 / 7$ & $0 / 4$ & $0.0 / 57.1$ \\
\hline & Motacilla alba (brood) & White wagtail, brood & $0 / 1$ & $0 / 1$ & $0.0 / 100.0$ \\
\hline \multirow[t]{4}{*}{ Passerine seedeaters } & Carduelis cannabina & Common linnet & $0 / 5$ & $0 / 0$ & $0.0 / 0.0$ \\
\hline & Carduelis carduelis & European goldfinch & $0 / 3$ & $0 / 0$ & $0.0 / 0.0$ \\
\hline & Carduelis chloris & European greenfinch & $70 / 20$ & $0 / 1$ & $0.0 / 5.0$ \\
\hline & Carduelis flammea & Common redpoll & $3 / 0$ & $0 / 0$ & $0.0 / 0.0$ \\
\hline Scolopacids & Tringa ochropus & Green sandpiper & $0 / 1$ & $0 / 0$ & $0.0 / 0.0$ \\
\hline \multirow[t]{2}{*}{ Sparrows } & Passer domesticus & House sparrow & $214 / 152$ & $38 / 51$ & $17.8 / 33.6$ \\
\hline & Passer montanus & Eurasian tree sparrow & $81 / 169$ & $1 / 41$ & $1.2 / 24.3$ \\
\hline Stream specialist & Motacilla cinerea & Grey wagtail & $0 / 1$ & $0 / 0$ & $0.0 / 0.0$ \\
\hline \multirow{7}{*}{$\begin{array}{l}\text { Terrestrial and low fly-catching } \\
\text { feeders }\end{array}$} & gerithacus rubecula & European robin & $25 / 4$ & $0 / 0$ & $0.0 / 0.0$ \\
\hline & Luscinia luscinia & Thrush nightingale & $0 / 1$ & $0 / 0$ & $0.0 / 0.0$ \\
\hline & Oenanthe oenanthe & Northern wheatear & $0 / 1$ & $0 / 0$ & $0.0 / 0.0$ \\
\hline & Phoenicurus phoenicurus & Common redstart & $0 / 3$ & $0 / 0$ & $0.0 / 0.0$ \\
\hline & Prunella modularis & Dunnock & $9 / 9$ & $4 / 2$ & $44.4 / 22.2$ \\
\hline & Saxicola rubetra & Whinchat & $0 / 3$ & $0 / 0$ & $0.0 / 0.0$ \\
\hline & Troglodytes troglodytes & Eurasian wren & $16 / 18$ & $0 / 0$ & $0.0 / 0.0$ \\
\hline \multirow[t]{3}{*}{ Thrushes } & Turdus merula & Common blackbird & $119 / 55$ & $63 / 44$ & $52.9 / 80.0$ \\
\hline & Turdus pilaris & Fieldfare & $3 / 0$ & $3 / 0$ & $100 / 0.0$ \\
\hline & Turdus viscivorus & Mistle thrush & $1 / 0$ & $0 / 0$ & $0.0 / 0.0$ \\
\hline
\end{tabular}


Table 2 continued

\begin{tabular}{lllllc}
\hline Ecological guilds & Species & Common name & $\begin{array}{l}\text { Number } \\
\text { tested W/S }\end{array}$ & $\begin{array}{l}\text { Number } \\
\text { positive W/S }\end{array}$ & $\begin{array}{l}\text { \% Campylobacter } \\
\text { positive W/S }\end{array}$ \\
\hline Tit-like birds & Certhia brachydactyla & Short-toed treecreeper & $1 / 0$ & $0 / 0$ & $0.0 / 0.0$ \\
& Certhia familiaris & Eurasian treecreeper & $0 / 1$ & $0 / 0$ & $0.0 / 0.0$ \\
& Cyanistes caeruleus & Eurasian blue tit & $30 / 15$ & $0 / 0$ & $0.0 / 0.0$ \\
& Lophophanes cristatus & European crested tit & $1 / 0$ & $0 / 0$ & $0.0 / 0.0$ \\
& Parus major & Great tit & $86 / 43$ & $2 / 1$ & $2.3 / 2.3$ \\
& Poecile palustris & Marsh tit & $5 / 3$ & $0 / 0$ & $0.0 / 0.0$ \\
Negulus regulus & Goldcrest & $1 / 0$ & $0 / 0$ & $0.0 / 0.0$ \\
No guild & Sitta europaea & Eurasian nuthatch & $1 / 0$ & $0 / 0$ & $0.0 / 0.0$ \\
& Bombycilla garrulus & Bohemian waxwing & $1 / 0$ & $0 / 0$ & $0.0 / 0.0$ \\
\hline
\end{tabular}

The species and number of birds tested for Campylobacter spp., and the prevalence in each bird species in winter (W) and summer (S)

Table 3 Campylobacter spp. prevalence in ecological guilds

\begin{tabular}{|c|c|c|c|c|c|c|}
\hline \multirow[t]{2}{*}{ Guild } & \multicolumn{3}{|l|}{ Winter } & \multicolumn{3}{|l|}{ Summer } \\
\hline & $\begin{array}{l}\text { Number } \\
\text { of samples }\end{array}$ & $\begin{array}{l}\text { Prevalence } \\
(\%)\end{array}$ & OR $(95 \% \mathrm{CI})$ & $\begin{array}{l}\text { Number } \\
\text { of samples }\end{array}$ & $\begin{array}{l}\text { Prevalence } \\
(\%)\end{array}$ & OR (95 \% Cl) \\
\hline Aerial insectivorous & - & - & - & 234 & 6.0 & $0.2(0.1-0.3)$ \\
\hline Foliage-gleaners & 26 & 0.0 & $N A^{a}$ & 104 & 12.5 & $0.4(0.2-0.7)$ \\
\hline Insectivorous seedeaters & - & - & - & 22 & 18.2 & $0.6(0.2-1,7)$ \\
\hline Open-land insectivorous & - & - & - & 10 & 50.0 & $2.5(0.7-8.8)$ \\
\hline Passerine seedeaters & 73 & 0.0 & NA & 28 & 3.6 & $0.1(0.01-0.7)$ \\
\hline Sparrows & 295 & 13.2 & 1.0 (reference) & 321 & 28.7 & 1.0 (reference) \\
\hline $\begin{array}{l}\text { Terrestrial and low } \\
\text { fly catching feeders }\end{array}$ & 50 & 8.0 & $0.6(0.2-1.7)$ & 39 & 5.1 & $0.1(0.03-0.6)$ \\
\hline Thrushes & 123 & 53.7 & $7.6(4.6-12.4)$ & 55 & 80.0 & $9.9(4.9-20.1)$ \\
\hline Tit-like birds & 125 & 1.6 & $0.1(0.03-0.5)$ & 62 & 1.6 & $0.04(0.01-0.3)$ \\
\hline Total & 692 & & & 875 & & \\
\hline
\end{tabular}

The odds-ratios (OR) and $95 \%$ confidence interval $(95 \% \mathrm{Cl})$ from the multivariate analysis of Campylobacter spp. prevalence in ecological guilds with $\geq 10$ birds sampled in winter and summer, with sparrows used as a reference

a Not applicable due to zero positive samples

birds eating food of animal or mixed animal and vegetable origin foraging on the ground and in vegetation close to the production buildings (Table 4). No association was found between Campylobacter spp. carriage and contact with slurry or migration range (data not shown).

\section{Herd type and Campylobacter species distribution}

C. jejuni was the most commonly isolated Campylobacter species in wild birds on all farm types, comprising $78.3 \%$ (58 out of 74) of wild bird isolates on cattle farms, $75.9 \%$ (101 out of 133) on pig farms and $89.9 \%$ (80 out of 89 ) on poultry farms (Table 1 ). The remaining isolates were almost entirely C. coli, of which 46 out of 48 isolates were found at the winter sampling.

Looking at the proportions of Campylobacter species in herd manure and the prevalence in wild birds at each of the
12 individual farms revealed a strong correlation between the prevalence of $C$. jejuni in both wild birds and the proportions in manure on cattle farms $\left(R^{2}=0.92\right)$, and a moderate correlation on poultry farms $\left(R^{2}=0.54\right)$. Likewise, a moderate correlation was found between $C$. coli in both wild birds and in pig manure $\left(\mathrm{R}^{2}=0.62\right.$; Fig. 1$)$. In contrast, no correlation was seen between $C$. coli in wild birds and in manure on cattle and poultry farms, or between $C$. jejuni in wild birds and in manure in pig herds (Fig. 1).

\section{Discussion}

A seasonal peak in the prevalence of Campylobacter spp. in wild birds was observed in summer. This was also found in a study of farm related Common Starling in the UK [12], and a study of Black-headed Gull (Larus ridibundus) in Sweden [23]. The underlying causes of 
Table 4 Factors associated with Campylobacter spp. carriage and specific bird behaviour during summer

\begin{tabular}{lc}
\hline Factor & Odds Ratio $\mathbf{( 9 5} \% \mathbf{C l})$ \\
\hline Feed & \\
Animal origin & $8.0(4.3-15.0)$ \\
Mixed animal and vegetable origin & $22.6(7.4-68.6)$ \\
Vegetable origin & 1.0 (reference) \\
Forage area & \\
In the air & $0.03(0.0-0.1)$ \\
On the ground & $1.03(0.4-2.8)$ \\
In the vegetation & $1.0($ reference) \\
Proximity to stables & \\
In or at stables & $42.72(14.2-128.5)$ \\
Around stables & 1.0 (reference) \\
\hline
\end{tabular}

seasonality in the epidemiology of Campylobacter spp. are not fully understood. However, seasonality is also a recognised factor in the pattern of Campylobacter spp. infections in poultry [2], and in the occurrence of human campylobacteriosis [1]. The vast majority (82.5\%) of Campylobacter spp. in wild birds in our study was isolated from thrushes and sparrows (Tables 2, 3), representing some of the most common wild bird species in Denmark (i.e. Common Blackbird, House Sparrow and Eurasian Tree Sparrow).

The Campylobacter spp. carriage rates of the farmrelated wild birds were found to be closely associated with the ecological guild (Table 3). Studies from Sweden [28] and Italy [35] have reported results for ecological guilds sampled at bird stations. The Swedish study found the highest Campylobacter spp. prevalence in wagtails, Common Starling and thrushes [28], in agreement with the results presented here. Common bird species such as the European Greenfinch, European Robin (Erithacus rubecula), Great Tit and Common Chaffinch (Fringilla coelebs) showed low Campylobacter spp. prevalence in both the Swedish study and the present study (Table 2). Our analysis identified feeding habit, forage area and proximity to stables as factors significantly associated with the carriage of Campylobacter spp. in wild birds (Table 4). This is in line with the results of the Italian study [35], where feeding habit was considered an important factor, and carnivorous birds foraging on the ground showed the highest prevalence of Campylobacter spp. A

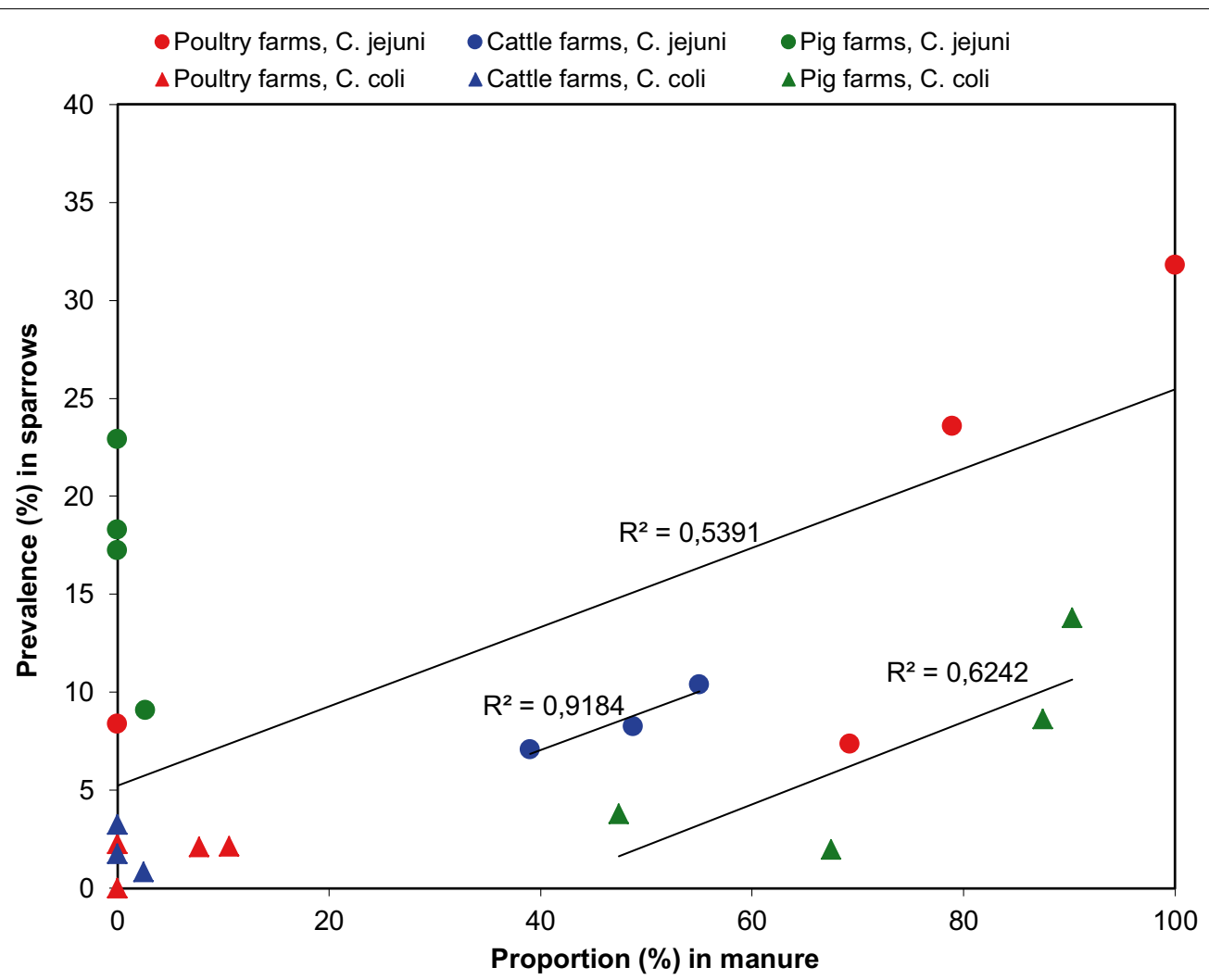

Fig. 1 Correlation between the prevalence (\%) of Campylobacter jejuni and C. coli in sparrows and the proportions (\%) of C. jejuni and C. coli in manure from cattle, pig and poultry herds. The prevalence, proportion and correlation coefficients $\left(R^{2}\right)$ on the regression lines are shown in red (poultry farms), blue (cattle farms) and green (pig farms) circles (C. jejuni) and triangles (C. coli) 
Japanese study [20] examined the correlation between the crop and actual stomach content and the prevalence of C. jejuni, and found a negative correlation between vegetable stomach content and $C$. jejuni colonisation. Several other studies have reported that omnivorous birds such as crows and gulls foraging close to areas with human garbage and sewage have a particular risk of high carriage rates [19, 20, 24, 25].

We found a correlation between the prevalence of $C$. jejuni in wild birds and proportions in both manure on cattle and poultry farms, and between $C$. coli in wild birds and pig manure (Fig. 1). However, this correlation can only account for part of the Campylobacter spp. epidemiology on the farms, since some of the $C$. jejuni and C. coli detected in the wild birds (i.e. the $C$. jejuni in birds on pig farms and the C. coli in birds on the cattle farms) could not be explained by the correlation to farm manure (Fig. 1, Table 1). It is likely that bird-to-bird transmission, or sources not included in this study were responsible for the observed Campylobacter spp. It is also possible that the farm animals and the wild birds both acquired Campylobacter spp. from the same sources, but became colonised by different species adapted to their specific gut environments. An interesting aspect for further research would be to investigate why the isolation rate of C. coli in the wild birds during the summer sampling was so low on all farms, and why the proportion of $C$. coli in the pig manure was also lower in summer $(60.2 \%)$ than in winter $(85.2 \%$; Table 1$)$.

Our study showed that in summer, sparrows caught at poultry or pig farms were more likely to carry Campylobacter spp. than sparrows caught at cattle farms. The reason for this remains speculative, though the majority of cows were at pasture during the summer months, thus potentially resulting in minimal contact with the sparrows close to the farm buildings. Further investigation should be performed in order to evaluate this.

We anticipated that wild birds and livestock occupying very close living space might share strains locally and that this might be a key point to understand the epidemiology of Campylobacter spp. in wild birds on livestock farms. We realise however, that our study suffers from an inferior resolution depth, as we summarised our results at the Campylobacter species level and not the genotype level. We may therefore have emphasised farm factors over strain factors, which were not measured. More recent studies using MLST have shown a large degree of host specificity $[12,17,36,37]$ and minimal overlap in MLST profiles of Campylobacter spp. from wild birds and from poultry, cattle and humans. There was a greater similarity between the level of $C$. jejuni found in Common Starling in Sweden and Common Starling in the UK, than there was between $C$. jejuni from Swedish Common Starling and their Swedish environment [37]. This segregation between the Campylobacter spp. strains in wild birds and the livestock reservoir is supported by a host attribution study [38] investigating the host association in seven housekeeping loci in 2732 published C. jejuni isolates from a number of sources including chicken, farm ruminants, and wild birds (passerine birds, ducks and geese). The main finding was that phylogenetically distinct $C$. jejuni lineages were associated with distinct wild birds, whereas in the farm environment, phylogenetically distant farm animals shared several $C$. jejuni lineages. Likewise, a possible adaptation of certain clonal complexes to flocks of barnacle geese in Finland has been found in a recent study [39]. Some studies note that wild birds may have a minor role in transmitting pathogenic $C$. jejuni strains to cattle $[11,13,15]$ and to humans $[10,13,15$, $16,39]$, whereas others found no evidence of transmission [12]. A recent study [40] found wild bird C. jejuni strains to be a consistent source of human disease in the UK, suggesting the existence of some more obscure epidemiological pathways between the wild bird reservoir and humans. From 2003 to 2013, the burden of campylobacteriosis cases attributed to wild birds was estimated at 10,000 per year in the UK. Therefore, it appears that the development of methods to control the transmission of Campylobacter spp. between livestock, humans, and wild birds requires better elucidation and understanding of the dynamics of transmission.

\section{Conclusions}

Based on the findings in this study, we conclude that the carriage of $C$. jejuni and C. coli in wild birds on livestock farms is correlated to the proximity to stables, feeding habits and forage areas on the ground and in vegetation. Birds with forage areas further away from livestock buildings or in the air, carried less Campylobacter spp. These findings suggest that wild birds may play a role in sustaining the epidemiology of Campylobacter spp. on farms, although this study is not able to elucidate the direction of the transmission, and further studies including genotyping are required.

\section{Authors' contributions}

MM, DLB, CR planned the study. BH coordinated the study and the laboratory work. MNS, JJM organised all sampling. JJM sampled the birds and MNS, SN sampled the livestock. EMN, MW, SN performed the Campylobacter spp. analyses. MC performed the data management and statistics. All authors read and approved the final manuscript.

\section{Author details}

${ }^{1}$ Danish Veterinary Laboratory, Department of Poultry, Fish and Fur Animals, 8200 Aarhus N, Denmark. ${ }^{2}$ Department of Microbiology, Danish Veterinary Laboratory, 1870 Frederiksberg C, Denmark. ${ }^{3}$ Natural History Museum of Denmark, University of Copenhagen, 1350 Copenhagen K, Denmark. ${ }^{4}$ The Danish Meatboard, 1609 Copenhagen V, Denmark. ${ }^{5}$ Center for Macroecology, Evolution, and Climate, Natural History Museum of Denmark, University of Copenhagen, 2100 Copenhagen $\varnothing$, Denmark. ${ }^{6}$ Present Address: National 
Food Institute, Technical University of Denmark, 2860 Søborg, Denmark. ${ }^{7}$ Present Address: Research Unit for Clinical Microbiology, University of Southern Denmark, 5000 Odense C, Denmark. ${ }^{8}$ Present Address: Department of Microbiology and Infection Control, Statens Serum Institut, 2300 Copenhagen S, Denmark. ${ }^{9}$ Present Address: Imperial College London, Silwood Park Campus, Ascot, Berkshire SL5 7PY, UK. ${ }^{10}$ Present Address: Chr. Hansen, 2970 Hørsholm, Denmark. ${ }^{11}$ Present Address: National Veterinary Institute, Technical University of Denmark, 1870 Frederiksberg C, Denmark. ${ }^{12}$ Present Address: Novo Nordisk, 4400 Kalundborg, Denmark. ${ }^{13}$ Present Address: Dianova Ltd., 8200 Aarhus N, Denmark.

\section{Acknowledgements}

We would like to thank the farmers and their families for their kindness and collaboration, and Klaus B. Fries, Henning Heldbjerg, Per A. Kjær, Jan B. Kristensen, Søren $\mathrm{H}$. Nielsen and Lars U. Rasmussen for their assistance with the collection of bird samples. We would also like to thank the laboratory technicians at the National Food Institute and the National Veterinary Institute for their technical support, and Monica Takamiya Wik for help with the manuscript. This project was supported by the Danish Ministry of Food, Fisheries and Agriculture under the programme for Campylobacter surveillance of livestock and mapping of environmental Campylobacter sources (1998-2001), grant No. FØSIO0-6.

\section{Competing interests}

The authors declare that they have no competing interests.

Received: 19 June 2015 Accepted: 21 January 2016

Published online: 03 February 2016

\section{References}

1. European Food Safety Authority. The European Union summary report on trends and sources of zoonoses, zoonotic agents and food-borne outbreaks in 2013. EFSA J. 2015. doi:10.2903/j.efsa.2015.3991.

2. EFSA Panel on Biological Hazards (BIOHAZ). Scientific Opinion on Campylobacter in broiler meat production: control options and performance objectives and/or targets at different stages of the food chain. EFSA J. 2011. doi:10.2903/j.efsa.2011.2105.

3. Murray CJL, Vos T, Lozano R, Naghavi M, Flaxman AD, Michaud C, et al. Disability-adjusted life years (DALYs) for 291 diseases and injuries in 21 regions, 1990-2010: a systematic analysis for the Global Burden of Disease Study 2010. Lancet. 2012;380:2197-223. doi:10.1016/ S0140-6736(12)61689-4.

4. Ray JCG, Ryan K. Sherris Medical Microbiology. 4th ed. New York: McGrawHill Medical; 2003. p. 378-80. doi: http://dx.doi.org/10.1036/0838585299.

5. EFSA Panel on Biological Hazards (BIOHAZ). Scientific Opinion on Quantification of the risk posed by broiler meat to human campylobacteriosis in the EU. EFSA J. 2010. doi:10.2903/j.efsa.2010.1437.

6. Friesema IHM, Havelaar AH, Westra PP, Wagenaar JA, van Pelt W. Poultry culling and campylobacteriosis reduction among humans, the Netherlands. Emerg Infect Dis. 2012;18:466-8. doi:10.3201/eid1803.111024.

7. Wagenaar JA, French NP, Havelaar AH. Preventing Campylobacter at the source: why is it so difficult? Clin Infect Dis. 2013;57:1600-6. doi:10.1093/cid/cit555.

8. Agunos A, Waddell L, Léger D, Taboada E. A systematic review characterizing on-farm sources of Campylobacter spp. for broiler chickens. PLoS ONE. 2014:9:e104905. doi:10.1371/journal.pone.0104905.

9. Craven SE, Stern NJ, Line E, Bailey JS, Cox NA, Fedorka-Cray P. Determination of the Incidence of Salmonella spp., Campylobacter jejuni, and Clostridium perfringens in Wild Birds near Broiler Chicken Houses by Sampling Intestinal Droppings. Avian Dis. 2000;44:715-20. doi:10.2307/1593118.

10. Colles FM, Dingle KE, Cody AJ, Maiden MCJ. Comparison of Campylobacter populations in wild geese with those in starlings and free-range poultry on the same farm. Appl Environ Microbiol. 2008;74:3583-90. doi:10.1128/AEM.02491-07.

11. Sippy R, Sandoval-Green CMJ, Sahin O, Plummer P, Fairbanks WS, Zhang $Q$, et al. Occurrence and molecular analysis of Campylobacter in wild life on livestock farms. Vet Microbiol. 2012;157:369-75. doi:10.1016/j. vetmic.2011.12.026.
12. Colles FM, McCarthy ND, Howe JC, Devereux CL, Gosler AG, Maiden MCJ. Dynamics of Campylobacter colonization of a natural host, Sturnus vulgaris (European starling). Environ Microbiol. 2009;11:258-67. doi:10.1111/j.1462-2920.2008.01773.x.

13. Kwan PSL, Barrigas M, Bolton FJ, French NP, Gowland P, Kemp R, et al. Molecular epidemiology of Campylobacter jejuni populations in dairy cattle, wildlife, and the environment in a farmland area. Appl Environ Microbiol. 2008;74:5130-8. doi:10.1128/AEM.02198-07.

14. Hughes LA, Bennett M, Coffey P, Elliott J, Jones TR, Jones RC, et al. Molecular epidemiology and characterization of Campylobacter spp. isolated from wild bird populations in northern England. Appl Environ Microbiol. 2009;75:3007-15. doi:10.1128/AEM.02458-08.

15. French N, Barrigas M, Brown P, Ribiero P, Williams N, Leatherbarrow $\mathrm{H}$, et al. Spatial epidemiology and natural population structure of Campylobacter jejuni colonizing a farmland ecosystem. Environ Microbiol. 2005;7:1116-26. doi:10.1111/j.1462-2920.2005.00782.x.

16. French NP, Midwinter A, Holland B, Collins-Emerson J, Pattison R, Colles $F$, et al. Molecular epidemiology of Campylobacter jejuni isolates from wild-bird fecal material in children's playgrounds. Appl Environ Microbiol. 2009;75:779-83. doi:10.1128/AEM.01979-08.

17. Broman T, Waldenstrom J, Dahlgren D, Carlsson I, Eliasson I, Olsen B. Diversities and similarities in PFGE profiles of Campylobacter jejuni isolated from migrating birds and humans. J Appl Microbiol. 2004;96:834-43. doi:10.1111/j.1365-2672.2004.02232.x.

18. Rosef O. The occurrence of Campylobacter fetus subsp. jejuni and Salmonella bacteria in some wild birds. Nord Vet Med. 1981;33:539-43.

19. Kapperud G, Rosef O. Avian wild life reservoir of Campylobacter fetus subsp. jejuni, Yersinia spp., and Salmonella spp. in Norway. Appl Environ Microbiol. 1983:45:375-80.

20. Ito K, Kubokura Y, Kaneko K, Totake Y, Ogawa M. Occurrence of Campylobacter jejuni in free-living wild birds from Japan. J Wildl Dis. 1988;24:46770. doi:10.7589/0090-3558-24.3.467.

21. Whelan CD, Monaghan P, Girdwood RWA, Fricker CR. The significance of wild birds (Larus sp.) in the epidemiology of Campylobacter infections in humans. Epidemiol Infect. 1988;101:259-67. doi:10.1017/ S0950268800054170.

22. Chuma T, Hashimoto S, Okamoto K. Detection of Thermophilic Campylobacter from Sparrows by Multiplex PCR: the role of sparrows as a source of contamination of broilers with Campylobacter. J Vet Med Sci. 2000;62:1291-5. doi:10.1292/jvms.62.1291.

23. Broman T, Palmgren H, Bergstrom S, Sellin M, Waldenstrom J, Danielsson-Tham M-L, et al. Campylobacter jejuni in Black-Headed Gulls (Larus ridibundus): prevalence, genotypes, and influence on C. jejuni epidemiology. J Clin Microbiol. 2002;40:4594-602. doi:10.1128/ JCM.40.12.4594-4602.2002.

24. Ramos R, Cerdà-Cuéllar M, Ramírez F, Jover L, Ruiz X. Influence of refuse sites on the prevalence of Campylobacter spp. and Salmonella serovars in seagulls. Appl Environ Microbiol. 2010;76:3052-6. doi:10.1128/ AEM.02524-09.

25. Keller J, Shriver IWG, Waldenström J, Griekspoor P, Olsen B. Prevalence of Campylobacter in wild birds of the mid-atlantic region, USA. J Wildl Dis. 2011;47:750-4. doi:10.7589/0090-3558-47.3.750.

26. Simberloff $D$, Dayan $T$. The guild concept and the structure of ecological communities. Annu Rev Ecol Syst. 1991;22:115-43. doi:10.1146/annurev. es.22.110191.000555.

27. Gotelli NJ, Graves GR, Rahbek C. Macroecological signals of species interactions in the Danish avifauna. Proc Natl Acad Sci USA. 2010;107:5030-5. doi:10.1073/pnas.0914089107.

28. Waldenstrom J, Broman T, Carlsson I, Hasselquist D, Achterberg RP, Wagenaar JA, et al. Prevalence of Campylobacter jejuni, Campylobacter lari, and Campylobacter coli in different ecological guilds and taxa of migrating birds. Appl Environ Microbiol. 2002;68:5911-7. doi:10.1128/ AEM.68.12.5911-5917.2002.

29. Skov MN, Madsen JJ, Rahbek C, Lodal J, Jespersen JB, Jørgensen $J C$, et al. Transmission of Salmonella between wildlife and meatproduction animals in Denmark. J Appl Microbiol. 2008;105:1558-68. doi:10.1111/j.1365-2672.2008.03914.x.

30. Skov MN, Carstensen B, Tornoe N, Madsen M. Evaluation of sampling methods for the detection of Salmonella in broiler flocks. J Appl Microbiol. 1999;86:695-700. doi:10.1046/j.1365-2672.1999.00715.x. 
31. Wedderkopp A, Rattenborg E, Madsen M. National surveillance of Campylobacter in broilers at slaughter in Denmark in 1998. Avian Dis. 2000;44:993. doi:10.2307/1593078.

32. Anonymous. Nordic Committé on Food Analysis, 2nd ed. Methodic no. 119: Campylobacter jejuni/coli detection in foods. Esbo, Finland: Statens Tekniska Forskningscentral; 1990

33. Dohoo IR, Martin W, Stryhn HE. Veterinary Epidemiologic Research. Charlottetown: P.E.I: University of Prince Edward Island; 2003. p. 335-69.

34. Kaiser A. A new multi-category classification of subcutaneous fat deposits of songbirds. J F Ornithol. 1993;64:246-55.

35. Sensale M, Cuomo A, Dipineto L, Santaniello A, Calabria M, Menna LF, et al. Survey of Campylobacter jejuni and Campylobacter coli in different taxa and ecological guilds of migratory birds. Ital J Anim Sci. 2006:5:2914. doi:10.4081/ijas.2006.291.

36. de Haan CPA, Lampén K, Corander J, Hänninen M-L. Multilocus sequence types of environmental Campylobacter jejuni isolates and their similarities to those of human, poultry and bovine C. jejuni isolates. Zoonoses Public Health. 2013;60:125-33. doi:10.1111/j.1863-2378.2012.01525.x.
37. Griekspoor P, Colles FM, McCarthy ND, Hansbro PM, Ashhurst-Smith C, Olsen B, et al. Marked host specificity and lack of phylogeographic population structure of Campylobacter jejuni in wild birds. Mol Ecol. 2013:22:1463-72. doi:10.1111/mec.12144.

38. Sheppard SK, Colles FM, MCCarthy ND, Strachan NJC, Ogden ID, Forbes $\mathrm{KJ}$, et al. Niche segregation and genetic structure of Campylobacter jejuni populations from wild and agricultural host species. Mol Ecol. 2011;20:3484-90. doi:10.1111/j.1365-294X.2011.05179.x.

39. Llarena A-K. Skarp-de Haan CPA, Rossi M, Hänninen M-L. Characterization of the Campylobacter jejuni population in the barnacle geese reservoir Zoonoses Public Health. 2015;62:209-21. doi:10.1111/zph.12141.

40. Cody AJ, McCarthy ND, Bray JE, Wimalarathna HML, Colles FM, van Rensburg MJ, et al. Wild bird associated Campylobacter jejuni isolates are a consistent source of human disease, in Oxfordshire, United Kingdom. Environ Microbiol Rep. 2015. doi:10.1111/1758-2229.12314.

\section{Submit your next manuscript to BioMed Central and we will help you at every step:}

- We accept pre-submission inquiries

- Our selector tool helps you to find the most relevant journal

- We provide round the clock customer support

- Convenient online submission

- Thorough peer review

- Inclusion in PubMed and all major indexing services

- Maximum visibility for your research

Submit your manuscript at www.biomedcentral.com/submit

O) Biomed Central 